\title{
Detection of Mycobacterium leprae DNA by Polymerase Chain Reaction in the Blood of Individuals, Eight Years after Completion of Anti-leprosy Therapy
}

\author{
Adalberto Rezende Santos, Vivian Balassiano**, Maria Leide W Oliveira**, \\ Marcia Aparecida da Silva Pereira*, Patricia Barros Santos*, \\ Wim Maurits Degrave*, Philip Noel Suffys*/+
}

Setor de Hanseníase, Departamento de Medicina Tropical *Laboratório de Biologia Molecular e Diagnóstico de

Doenças Infecciosas, Departamento de Bioquímica e Biologia Molecular, Instituto Oswaldo Cruz-Fiocruz,

Av. Brasil 4365, 21045-900 Rio de Janeiro, RJ, Brasil **Universidade Federal do Rio de Janeiro,

Rio de Janeiro, RJ, Brasil

Thirty eight patients with indeterminate leprosy (HI), at least 4 to 6 years after discharge from multibacillary $(M B)$ or paucibacillary $(P B)$ schemes of anti leprosy multidrug therapy $(M D T)$, were submitted to traditional diagnostic procedures for leprosy and to polymerase chain reaction (PCR) analysis of different clinical samples for detection of Mycobacterium leprae DNA. No significant difference was observed for any of the parameters analyzed between $P B$ or $M B$ schemes of treatment and no indications were found for more efficient outcome of HI using the MB scheme. Remarkably, 18 (54.5\%) of the individuals were PCR positive in at least one of the samples: positivity of PCR was highest in blood samples and four individuals were PCR positive in blood and some other sample. Upon comparison of PCR results with clinical and histopathological parameters, no correlation was found between PCR-positivity and eventual relapse. This is the first report on detection of $\mathrm{M}$. leprae DNA in PB patients, more than half a decade after completion of MDT, suggesting that live bacilli are present and circulating much longer than expected, although reinfection of the individuals can not be excluded. Overall, we feel that because of the high sensitivity of the assay, extreme care should be taken about association of PCR results, efficacy of treatment and disease status.

Key words: Mycobacterium leprae - PCR - diagnosis - therapy - post-treatment - paucibacillary leprosy

Leprosy is a chronic infectious disease caused by Mycobacterium leprae and is still a public health problem in many developing countries, including Brazil with 88,029 registered cases and a prevalence of 5.51 per 10.000 at the end of 1997 (Brazilian Ministry of Health 1998). According to the clinical spectrum proposed by Ridley and Jopling (1966), leprosy is characterized by two polar forms: a paucibacillary tuberculoid (TT) and a multibacillary lepromatous lepromatous (LL) form, and by the intermediate forms borderline tuberculoid (BT), borderline borderline (BB) and borderline lepromatous (BL) leprosy. Indeterminate (HI) leprosy is an early and instable stage of the disease and, depending on the host resistance, migrates through the clinical spectrum to one of the definitive forms or goes

\footnotetext{
This work was supported by $\mathrm{CNPq}$ and by CBAB. ${ }^{+}$Corresponding author. Fax: +55-21-2270.9997. E-mail: psuffys@gene.dbbm.fiocruz.br.

Recieved 23 February 2001

Accepted 19 June 2001
}

to self healing. Patients are treated with two or three different drugs (multidrug therapy; MDT) during a period of six months to one year, depending on the clinical form of the disease.

For correct implementation of MDT, the World Health Organization (WHO) classifies leprosy either as multibacillary (MB) or paucibacillary (PB), according to the Bacteriological Index (BI; WHO 1982). In Brazil, MDT was implemented in 1986 and because bacterioscopy was not applied at all basic health units at that time, the Brazilian National Program for Leprosy Control recommended the use of the Mitsuda test as a parameter for establishing the treatment regimen in cases of HI leprosy (Ministério da Saúde 1986). Patients with negative response to Mitsuda were included in the MB group but in some reference centers such patients were treated according to the recommendation of WHO. Leprosy has a long incubation period, a wide spectrum of clinical manifestations and the causative agent $M$. leprae can not be grown in vitro. This turns detection of subclinical infection and of early stages of the disease, principally the PB forms difficult. Furthermore, evaluation of efficacy of anti 
leprosy chemotherapy is complicated and the only reliable method to determine bacilli viability is the mouse foot pad technique (Shepard 1960), which is expensive, time consuming and can be used only for MB samples (Baohong 1987). In consequence, evaluation of MDT is mostly based on determination of the frequency of relapse and on the detection of M. leprae DNA by PCR (THELEP 1987, Boerrigter et al. 1991, Williams et al. 1992, Jamil et al. 1993).

Because of Brazil's particular situation where cases with HI leprosy had been treated both with $\mathrm{PB}$ and MB MDT schemes, it was possible to evaluate efficiency of these treatment schemes in PB patients, in a retrospective study on individuals that had completed treatment, by comparing PCRmediated detection of M. leprae DNA with clinical, histopathological and laboratorial data.

\section{MATERIALS AND METHODS}

Patients - This study included 38 patients with the HI form of leprosy: 17 (44.7\%) after treatment with the MB MDT scheme and 21 (55.3\%) after treatment with the PB MDT scheme, consisting respectively of 12 supervised monthly doses of rifampicin $600 \mathrm{mg}$, clofazimine $50 \mathrm{mg}$ and dapsone $100 \mathrm{mg}$ for a maximum of 18 months or 6 supervised monthly doses of $600 \mathrm{mg}$ rifampicin and daily self administered doses of $100 \mathrm{mg}$ dapsone for a maximum of 9 months (WHO 1982). Patients had been evaluated at the National Reference Center for Leprosy of the Oswaldo Cruz Foundation in Rio de Janeiro (14 PB); at the National Reference Center for Leprosy Alfredo da Mata, Manaus (7 PB and 1 $\mathrm{MB})$; at the Health Center Washington Luis from São Gonçalo (5 MB); at the Municipal Health Center from Duque de Caxias (5 MB) and at the Health Center Vasco Barcelos from Nova Iguaçu (6 MB). Patients were selected on basis of the following criteria: having suffered $\mathrm{HI}$ and having (i) an initial baciloscopic index equal to zero; (ii) negative Mitsuda test $(<5 \mathrm{~mm})$ and (iii) been discharged from regular treatment for at least $6(\mathrm{~PB})$ or $4(\mathrm{MB})$ years.

Clinical, histopathological and laboratorial tests for leprosy - Clinical and neurological examination were performed according to routine procedures and the number of lesions and areas with decreased sensitivity, alteration in thermal, painful and tactic sensitivity and the degree of disability of the patient were determined. Slit skin smears were sampled for BI determination from each individual and the Mitsuda test was performed following standard procedures of the Brazilian Ministry of Health (Ministério de Saúde 1986, 1993, 1994). The Mitsuda test was considered positive when at least $5 \mathrm{~mm}$ of erithema and induration was observed. Histopathological examination was performed only in cases where maculae or anesthetic area(s) were present. All procedures were in accordance with standards of the Ethical Committee.

Sample processing and PCR - Blood, lymph, hair, nasal secretion and skin biopsy were collected and processed as described earlier (Santos et al. 1993, 1995). Amplification conditions were as described (Santos et al. 1993), using a M. leprae-specific repetitive target sequence (Woods \& Cole 1989). For each PCR, a $1 \mathrm{ng}, 100 \mathrm{pg}$ and $100 \mathrm{fg}$ sample of purified $M$. leprae DNA were included as positive controls and a negative control for every five samples. Amplification was verified by gel electrophoresis and ethidium bromide staining and PCR-negative samples were reconstituted with 1 ng of purified $M$. leprae DNA and submitted to a second amplification to verify the presence of PCRinhibitors.

Statistical analysis - Statistical significance of differences was verified using Yates corrected $\chi^{2}$ and p-values with a $95 \%$ confidence limit, or using the Fisher Exact Test.

\section{RESULTS}

Clinical and neurological examination - Six to eight years after treatment discharge, at least one residual lesion was observed in 3 of the patients $(17.6 \%)$ that had been treated with the MB scheme and 8 of the patients $(38 \%)$ that had received the PB scheme $(p=0.3)$. Local paresthesia was observed in 10 individuals at the site of the initial lesion and in one individual in a different area; none had other dermatological or neurological sequelae.

Mitsuda test - All individuals were initially Mitsuda negative and from the 23 individuals from whom Mitsuda testing was also available after treatment, $15(65.2 \%)$ had become Mitsuda positive while $8(34.8 \%)$ maintained a negative response. From the individuals with second Mitsuda testing, 5 out of $10(50 \%)$ that had been treated with as MB and 10 out of the $13(76.9 \%)$ that thad been treated as PB $(p=0.36)$ became positive. Eight out of the 11 cases with persisting lesions were re-evaluated: 7 $(87.5 \%)$ demonstrated a conversion in Mitsuda response while only one (12.5\%) remained negative.

$B I$ - The BI was determined in $31(81.6 \%)$ cases and AFB were detected in 2 cases, presenting a BI of less than one according to the Ridley and Jopling scale (Ridley \& Hilson 1967); both patients had been treated with the MB scheme.

Histopathological examination - For technical reasons, histopathology could only be performed upon re-evaluation in 4 individuals ( 3 from the group treated with PB and one of the group treated with PB scheme). In all samples, the results were unspecific and no AFB were found. 
PCR analysis - Ninety samples from 33 subjects, $14(42.4 \%)$ treated as MB and $19(57.6 \%)$ with the PB scheme, were submitted to PCR. Samples from 18 different cases (54.5\%) had positive PCR and no significant difference of PCR positivity between $\mathrm{PB}$ and $\mathrm{MB}$ treated individuals was found in any specific sample (Table I); PCR positivity was however higher in individuals that had been treated with the MB scheme (Table II). Among the patients that had positive PCR in blood, 4 were also positive in at least another sample: 2 in biopsy, one in biopsy and nasal secretion and one in lymph and nasal secretion. No significant statistical correlation was found between conversion in Mitsuda reaction and PCR-positivity but significant more positive PCR was observed in individuals where AFB had been observed in slit skin smears (Table II). From the 66 PCR-negative samples, 63 were tested for the presence of inhibitors: 10 of these (5 blood samples and 5 nasal secretions) demonstrated the presence of inhibitors and could eventually be considered as false negative. No further attempts to get rid of inhibition in these samples were performed.

\section{DISCUSSION}

Although leprosy is one of the older infectious diseases described to man, many questions on epidemiology and pathology of the disease and on mechanisms of immune response of the host remain. Upon implementation of MDT, several clinical trials to evaluate the efficacy of schemes proposed for treatment of MB and PB leprosy have been performed (THELEP 1987, Boerrigter et al. 1991). Although amplification of nucleic acids seems to be the most sensitive way to monitor changes in bacterial load during chemotherapy, few studies focused on the use of PCR as a method for evaluation of antileprosy chemotherapy. We therefore included PCR in the diagnostic procedures used for reevaluation of individuals, half a decade after suffering from indeterminate leprosy and being discharged from treatment with either PB or MB MDT schemes.

The number of individuals still presenting residual lesions after treatment was comparable with that found in another study on patients with PB forms of leprosy (Dhir et al. 1986). Bacteriological examination revealed the presence of AFB in 2 patients, and, surprisingly, both of them had been treated with the MB scheme. It is unlikely that the presence of AFB detected by microscopy is attributed to persistent bacteria because of the low detection limit of the technique; detection of AFB in these individuals could be due to re-infection or to relapse from MB leprosy after having been wrongly classified as PB.

Upon comparison of results obtained by PCR with those obtained by conventional diagnostic methods, an unexpectedly high number of cases presented positive PCR. No relation was found between detection of $M$. leprae DNA and presence of residual lesions or conversion of the Mitsuda reaction. Three of the four biopsy samples were PCR positive in spite of their negative BI: 2

TABLE II

PCR results obtained in different clinical settings

\begin{tabular}{llrl}
\hline Clinical settings & & PCR+ & $\begin{array}{l}\text { Statistical } \\
\text { analysis }\end{array}$ \\
\hline Treatment scheme & $\begin{array}{l}14 \mathrm{MB} \\
19 \mathrm{~PB}\end{array}$ & $\begin{array}{r}10 \\
8\end{array}$ & $\mathrm{p}=0.18$ \\
& & 4 & \\
Mitsuda conversion & $8-$ & 11 & $\mathrm{p}=0.26$ \\
& $15+$ & 2 & \\
Bacteriological Index & $28-$ & 2 & $\mathrm{p}=0.0001$ \\
\hline
\end{tabular}

$a$ : Fisher excact test; MB: multibacillary leprosy; PB: paucibacillary.

TABLE I

PCR results obtained in different kinds of clinical samples

\begin{tabular}{|c|c|c|c|c|}
\hline \multirow{2}{*}{$\begin{array}{l}\text { Sample } \\
\text { Hair bulbs (26) }\end{array}$} & \multicolumn{2}{|c|}{ Treatment scheme } & \multirow{2}{*}{$\frac{\mathrm{PCR}+}{2}$} & \multirow[t]{2}{*}{ Statistical significance $^{a}$} \\
\hline & PB & 15 & & \\
\hline & MB & 11 & 0 & $\mathrm{p}=0.21$ \\
\hline \multirow[t]{2}{*}{ Blood (17) } & $\mathrm{PB}$ & 7 & 5 & \\
\hline & MB & 10 & 7 & $\mathrm{p}=0.95$ \\
\hline \multirow{2}{*}{ Nasal secretion (13) } & $\mathrm{PB}$ & 6 & 0 & \\
\hline & MB & 7 & 3 & $\mathrm{p}=0.07$ \\
\hline \multirow[t]{2}{*}{ Lymph (30) } & $\mathrm{PB}$ & 16 & 2 & \\
\hline & MB & 14 & 2 & $\mathrm{p}=0.89$ \\
\hline \multirow[t]{2}{*}{ Skin biopsy (4) } & PB & 3 & 2 & \\
\hline & MB & 1 & 1 & $\mathrm{p}=0.50$ \\
\hline
\end{tabular}

$a$ : Fisher exact test; PB: paucibacillary; MB: multibacillary leprosy 
biopsies were sampled from individuals that had been treated with the PB scheme and also had a PCR positive blood sample; another was isolated from an individual that had been treated with the MB scheme and was PCR-positive in blood and in nasal secretion. Two of these cases were re-evaluated after performing PCR but the persistent lesions from which the biopsy had been taken were considered residual. The 2 patients with positive $\mathrm{BI}$ in slit-skin smear also demonstrated positive PCR in their blood sample but except for one case (data not shown), no correlation between the results of $\mathrm{BI}$ and PCR with the clinical/neurological status of these patients whithin the time frame of our study was observed. Detection of bacilli in PB patients discharged such a long period after treatment has not been reported earlier. According to Jamil et al. (1993) PCR-mediated detection of M. leprae DNA was achieved 24 months after starting MDT in MB but not in PB patients. According to WHO, persistent bacilli can be detected in individuals, 20 years after having been treated with dapsone monotherapy (THELEP 1987) and in about 10\% of MB patients, persisters could not be killed by any drug combination; again, the number of persisters seemed related to bacterial load (Rafi et al. 1995).

From the different samples submitted to PCR, the highest number of PCR positives was obtained in blood (Table I). Detection of bacillaemia using conventional techniques has been reported both for $\mathrm{MB}$ and $\mathrm{PB}$ forms of leprosy and during leprosy reaction (Manja et al. 1972, Raval et al. 1982, Jayapal \& Bhatia 1986, Kaur \& Handa 1986, Chatterjee et al. 1988, Sen et al. 1989, Zawar et al. 1993), as well as by PCR in our own studies in BT and TT patients (Santos et al. 1995). These studies however were performed on patients before treatment and AFB have as far as we know not been reported in blood by conventional techniques longer than six months after-treatment. Considering the short-half life of phagocytic blood cells and the long period after treatment before performing PCR, we find it very unlikely that DNA from dead bacilli was amplified, therefore suggesting PCR-mediated detection of subclinical infection with viable $M$. leprae. It is tempting to conclude that we detected persistent bacilli, but re-infection cannot be excluded because most individuals included in the study live in an endemic region for leprosy. It is not possible to draw final conclusions on the clinical significance of the positive PCR in blood of 12 individuals, but the fact that 4 of them also had positive PCR in another samples show that this needs further investigation.

This is the first report on detection of M. leprae in MDT-treated PB patients after a long period of follow up and the high level of PCR-positive cases suggests that in the spite of completion of what is considered "treatment untill cure", part of the bacterial population is circulating in the body without apparently cause any damage to the host. This observation, together with the fact that only a small number of infected individuals actually develops active disease suggests that PCR results should always be linked to clinical evaluation and used only for confirmation of cases that are difficult to diagnose using conventional techniques (Kaur \& Handa 1986, Santos et al. 1997) and for definition of populations that are at risk of developing the disease. Our findings also show that evaluation of leprosy chemotherapy using DNA amplification systems should be interpreted with care and we are worried about the high number of individuals carrying "live bacilli" after MDT treatment. More studies are needed to determine whether these individuals are at a higher risk for developing relapse.

\section{ACKNOWLEDGEMENTS}

To the staff of the Leprosy Outpatient Unit for sample collection and to Edson CA Albuquerque for Bacteriological Index determination

\section{REFERENCES}

Baohong J 1987. Drug susceptibility testing of Mycobacterium leprae. Int J Lepr 55: 830-835.

Boerrigter G, Ponnighaus JM, Fine PEM, Wilson RJ 1991. Four year follow-up results of a WHO-recommended regimen in paucibacillary leprosy in patients in Malawi. Int J Lepr 59: 255-261.

Brazilian Ministry of Health 1998. Hansen's Disease in Brazil Progress Towards Elimination, National Health Foundation, Cenepi, Secretariat of Health Policy, Brasília.

Chatterjee G, Kaur S, Sharma. VK, Vaishnavi C, Kaur I 1988. Bacillaemia in leprosy: correlation with slitsmear and nasal smears. Indian J Lepr 60: 535-541.

Dhir R, Guha PK, Singh G 1986. Short term chemotherapy of paucibacillary leprosy. Indian J Lepr 58: 549-554.

Jamil S, Keer JT, Lucas SB, Deckrell HM, Chiang TJ, Hussain R, Stoker NG 1993. Use of the polymerase chain reaction to access efficacy of leprosy chemotherapy. Lancet 342: 264-267.

Jayapal V, Bhatia VN 1986. Bacillaemia in smear negative leprosy. Lepr India 58: 661.

Job CK, Jayakumar J, Williams DL, Gillis TP 1997. Role of polymerase chain reaction in the diagnosis of early leprosy. Int J Lep 65: 461-464.

Kaur B, Handa F 1986. Correlation of bacillaemia with clinical types of leprosy. Ind J Derm Vener Lepr 52: 272-274.

Manja KS, Bedi BMS, Kasturi G, Kirchheimer WF, Balasubrahmanyan M 1972. Demonstration of $M y$ cobacterium leprae and it's viability in the peripheral blood of leprosy patients. Lepr Rev 43: 181187. 
Ministério da Saúde 1986. Manual de Normas e Procedimentos para Implantação da Multidrogaterapia, Brasília.

Ministério da Saúde 1993. Guia de Controle da Hanseníase. Fundação Nacional de Saúde, Brasília.

Ministério da Saúde 1994. Guia para o Controle da Hanseníase, 2nd ed., Coordenação Nacional de Dermatologia Sanitária, Centro Nacional de Epidemiologia, Fundação Nacional de Saúde, Brasília.

Rafi A, Donoghue HD, Stanford JL 1995. Application of polymerase chain reaction for the detection of Mycobacterium leprae DNA in specimens from treated leprosy patients. Int J Lepr 63: 42-47.

Raval SN, Sengupta U, Ramu G 1982. A study of continuous bacillaemia in borderline and lepromatous type of leprosy. Lepr India 54: 623-633.

Ridley DS, Hilson GRF 1967. A logarithmic index of bacilli in biopsies. Int J Lepr 35: 184-186.

Ridley DS, Jopling WH 1966. Classification of leprosy according to immunity - a five group system. Int $J$ Lepr 34: 255-273.

Santos AR, de Miranda AB, Sarno EN, Suffys PN, Degrave WM 1993. Use of PCR- mediated amplification of Mycobacterium leprae DNA in different types of clinical samples for the diagnosis of leprosy. J Med Microbiol 39: 298-304.

Santos AR, Goes JTF, Nery JAC, Duppre NC, Gallo MEN, Suffys PN, Degrave WM 1995. Evaluation of PCR mediated DNA amplification in non-Invasive biological specimens for subclinical detection of M. leprae. FEMS Immunol and Med Microbiol 504: 113-120.
Santos AR, Nery JAC, Duppre NC, Gallo MEN, Filho JTG, Suffys PN, Degrave WM 1997. Use of the polymerase chain reaction in the diagnosis of leprosy. J Med Microbiol 46: 170-172.

Sen R, Sehgal PK, Singh U, Yadav MS, Chaudhary SD, Sikka R 1989. Bacillaemia and bone marrow involvement in leprosy. Lepr India 61: 445-452.

Shepard CC 1960. The experimental disease that follows the infection of human leprosy bacilli into footpads of mice. J Exp Med 112: 445-454

THELEP 1987 - Subcommittee on clinical trials of chemotherapy of leprosy, Scientific Working Group of the UNDP/World Bank/WHO Special Programme for Research and Training in Tropical Diseases, Persisting Mycobacterium leprae among THELEP trial patients in Bamako and Chingleput. Lepr Rev 58: 325-337.

WHO-World Health Organization 1982. Study group chemotherapy of leprosy for control programs, Tech Rep Ser 675, Geneve.

Williams DL, Gillis TP, Fialho P, Job CK, Gelber RH, Hill C, Izumi S 1992. Detection of Mycobacterium leprae and the potential for monitoring antileprosy drug therapy directly from skin biopsies by PCR. Molec Cell Probes 6: 401- 410.

Woods SA, Cole STA 1989. Rapid method for the detection of potentially viable Mycobacterium leprae in human biopsies: a novel application of PCR. FEMS Microbiol Lett 65: 305-310.

Zawar PB, Holla V, Patil SM 1993. Bacillaemia in lepra reaction. Its correlation with liver pathology. Lepr India 55: 570-575. 
1134 M. leprae DNA in Blood - Adalberto Rezende Santos et al. 